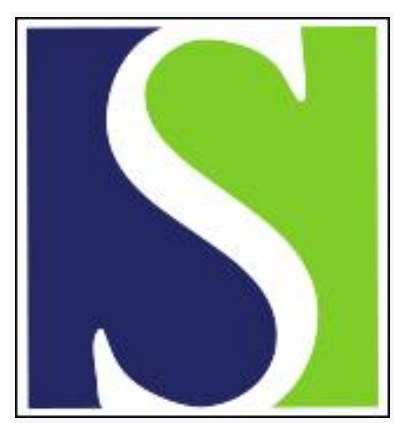

Scand J Work Environ Health 1989;15(4):296-301

https://doi.org/10.5271/sjweh.1850

Issue date: Aug 1989

Lung function and bronchial reactivity in aluminum potroom workers.

by Larsson K, Eklund A, Arns R, Lowgren H, Nystrom J, Sundstrom G, Tornling $\mathrm{G}$

Affiliation: National Institute of Occupational Health, Solna, Sweden.

This article in PubMed: www.ncbi.nlm.nih.gov/pubmed/2772584

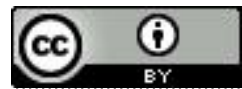




\title{
Lung function and bronchial reactivity in aluminum potroom workers
}

\author{
by Kjell Larsson, MD, ${ }^{1}$ Anders Eklund, MD, ${ }^{2}$ Robert Arns, MD, ${ }^{3}$ Hans Löwgren, MD, ${ }^{4}$ \\ John Nyström, MD, ${ }^{4}$ Gunnar Sundström, MD, ${ }^{5}$ Göran Tornling, MD ${ }^{2}$
}

\begin{abstract}
LARSSON K, EKLUND A, ARNS R, LÖWGREN H, NYSTRÖM J, SUNDSTRÖM G, TORNLING G. Lung function and bronchial reactivity in aluminum potroom workers. Scand $J$ Work Environ Health 1989;15:296-301. Lung function and bronchial reactivity were measured in 38 aluminum potroom workers with no airway symptoms and in 20 healthy referents (office workers). All of the participants were nonsmokers. The magnitude of exposure to airborne dust (alumina) and fluorides was determined. The aluminum potroom workers had obstructive lung function impairment with a significant decrease in expiratory flow and an increase in residual volume. Diffusing capacity was found to be lower than in the referents. No bronchial hyperreactivity was found in the aluminum potroom workers. The exposure to inhaled alumina and particulate and gaseous fluorides in the plant was low, 15-20\% of the Swedish exposure limits. The finding of only modest lung function alterations with no bronchial hyperreactivity in the aluminum potroom workers is not consistent with the results of other authors. This discrepancy can probably be explained by the fact that the exposure to inhaled contaminants in the investigated aluminum plant was low.
\end{abstract}

Key terms: aluminum, exposure measurements, fluorides, occupational.

Aluminum potroom workers are exposed to several airborne contaminants, eg, aluminum oxide (alumina), gaseous and particulate fluorides, and sulfur dioxide. Working in this environment has been shown to give symptoms such as cough, dyspnea, wheezing, and phlegm $(1,2)$. Obstructive lung function impairment (2) and bronchial hyperreactivity $(1,3,4)$ have been reported in aluminum potroom workers. There are also data indicating that aluminum potroom workers have an increased prevalence of "asthma-like symptoms" (5) or asthma which is not related to atopy $(6,7)$. These findings have not been confirmed by the results of other investigations $(2,8,9)$. Furthermore, there are observations indicating that exposure to airborne alumina causes pulmonary fibrosis (10-13).

The inhalation of airborne contaminants in potrooms of aluminum plants thus seems to affect the lungs and airways of workers and lead to both obstructive and restrictive pulmonary changes. However, aside from the measurement of lung function parameters such as forced expiratory volume in $1 \mathrm{~s}\left(\mathrm{FEV}_{1.0}\right)$ and vital capacity (VC), no extensive lung function studies have, to our knowledge, been performed on aluminum potroom workers. Therefore, the aim of the present study was to undertake a detailed investigation of the

1 National Institute of Occupational Health, Solna, Sweden.

2 Department of Thoracic Medicine, Karolinska Hospital, Stockholm, Sweden.

3 GA Metall Ltd, Sundsvall, Sweden.

4 Department of Pulmonary Medicine, Sundsvall, Sweden.

5 Department of Clinical Physiology, Sundsvall, Sweden.

Reprint requests to: Dr Kjell Larsson, Unit of Lung Physiology, IFL, National Institute of Occupational Health, S-171 84 Solna, Sweden. lung function of aluminum potroom workers. We also wanted to determine whether these workers have an increased bronchial reactivity and, if alterations in lung function or bronchial reactivity were found, to what extent these changes are related to the magnitude of exposure to airborne alumina and particulate and gaseous fluorides.

\section{Subjects and methods}

\section{Subjects}

Thirty-eight male aluminum plant workers [mean age 39 (range $21-63$ ) years] working in a potroom with daily exposure to airborne alumina and fluorides and 20 male office workers (the referents) from the same plant [mean age 48 (range 24-65) years] participated in the study. The subjects of the exposed group had been working in the aluminum plant for an average of 13.6 (SEM 1.4, range 1-32) years. None of the subjects in the reference group had been exposed to airborne contaminants in the aluminum plant with the exception of three, who, more than five years prior to the present investigation, had had low exposure in the potroom (maintenance work) for less than two years. None of the subjects in the two groups had been smokers in the two years prior to the time of the trial. In the reference group eight were ex-smokers [7.4 (SEM 2.0) pack-years], and in the exposed group 14 were exsmokers [11.4 (SEM 2.5) pack-years]. There was no significant difference in earlier smoking habits. All of the participants were requested to complete a questionnaire and an oral interview with regard to present and former airway and allergic symptoms. Cough, phlegm, dysp- 
nea, rhinoconjunctivitis, atopic dermatitis, urticaria, and symptoms of asthma were inquired about. With the exception of minimal pleural thickening in one subject and pleural plaque in one, all the participants had a normal chest radiograph. All the subjects gave their informed consent to participate in the study, which had the approval of the Ethics Committee of the University of Umeå.

\section{Lung function measurements}

All the participating subjects completed the lung function study and the bronchial provocation tests. The lung function tests were performed in the upright sitting position. The tests were repeated two or more times unless otherwise stated, and the best value was chosen. The lung volumes have been corrected to body temperature and pressure saturated with water vapor (BTPS). The signals from a dry rolling seal spirometer, the nitrogen meter with a pneumotachograph, and a body box of the hybrid type were transformed and transmitted to a computer through a microprocessor controlled by an analogue-digital converter. The computer was a scientific type microcomputer (HewlettPackard 9816) and the applied software was written in the laboratory.

Vital capacity was obtained from a slow expiration from the total lung capacity (TLC) to residual volume. The total lung capacity and residual volume were measured in a body box according to the method described by DuBois et al (14). The predicted normal values for the static lung volumes were taken from Grimby \& Söderholm (15).

The dynamic lung volumes and flows were obtained from a maximally forced expiration six or more seconds in duration after a maximal inspiration. The starting point of the expiration was obtained by backward extrapolation to the zero volume change of the steepest part of the volume-time curve. The $\mathrm{FEV}_{1.0}$, the maximal expiratory flow at $50 \%$ of the expired forced vital capacity $\left(\mathrm{MEF}_{50}\right)$, and the mean transit time from the start to $6.3 \mathrm{~s}$ of the expiration were calculated from the curve (out of three) with the highest sum of the forced vital capacity and the FEV ${ }_{1.0}$. The predicted normal values, according to age and body length, were those of Berglund et al (16) for FEV $\mathrm{F}_{1.0}$ and those of Hedenstierna et al (17) for $\mathrm{MEF}_{50}$. The predicted normal values for the mean transit time were taken from Macfie et al (18). The $\mathrm{FEV}_{1.0}$ was expressed as the FEV \% $\left[\left(100 \times \mathrm{FEV}_{1.0}\right) /\right.$ slow VC], and the predicted normal values of Morris et al (19) were used.

The single breath nitrogen washout maneuver was performed by measuring the nitrogen concentration during a slow expiration from the total lung capacity to the residual volume after a full inspiration (from residual volume to total lung capacity) of oxygen. The closing point and the slope of the alveolar plateau (phase III) were determined from the curve of the nitrogen concentration as a function of volume on the com- puter screen by the use of an interactive technique with cursors. The closing volume was defined as the volume between the closing point and the end of the expiration. Closing capacity (CC) was calculated as the sum of the residual volume and closing volume. The closing capacity was also expressed as a percentage of the total lung capacity (CC/TLC \%). Phase III was the slope of the alveolar plateau as the change in the nitrogen concentration per liter of expired air. It was defined as the average slope from the onset of the alveolar plateau to the closing point. For these calculations the curve with the greatest volume (which should be close to the vital capacity) was chosen. The reference values were taken from Hedenström et al (20).

The single breath pulmonary diffusion capacity for carbon monoxide $\left(\mathrm{TL}_{\mathrm{COSB}}\right)$ (in millimoles per minute kilopascals) was the mean of two measurements. If the second value differed more than $10 \%$ from the first, an additional measurement was performed. The method followed the recommendations of the European Coal and Steel Working Party (21) as it is applied in the automatic test system by Mijnhardt (Diffusimat 2000). The reference equation was taken from Salorinne (22).

\section{Bronchial challenge test}

Bronchial provocation comprised inhalations of methacholine in increasing concentrations, each increment of the dose representing a fourfold increase in the concentration. After the diluent was inhaled, the methacholine challenge began at a concentration of 0.5 $\mathrm{mg} / \mathrm{ml}$. The inhaled solution was nebulized in a DeVilbiss nebulizer (no 40) (DeVilbiss Company, Somerset, Pennsylvania, United States) and was inhaled by tidal breathing during $1 \mathrm{~min}$. The breathing pattern of $2 \mathrm{~s}$ of inspiration and $2 \mathrm{~s}$ of expiration was guided by a metronome. Peak expiratory flow (PEF) was measured $3 \mathrm{~min}$ after the inhalation maneuver was started, and the best value of three measurements was chosen. The provocation was stopped when the peak expiratory flow decreased by $\geq 20 \%$ of the baseline values, ie, the values obtained before inhalation of the diluent or after the inhalation of the highest concentration (32 $\mathrm{mg} / \mathrm{ml}$ ). The $\mathrm{PC}_{20} \mathrm{PEF}$ and $\mathrm{PC}_{10} \mathrm{PEF}$, ie, the concentration of methacholine that yields a peak expiratory flow decrease of 20 and $10 \%$ from the baseline values, respectively, were calculated.

\section{Exposure to airborne alumina and fluorides}

Exposure was assessed for different work tasks from measurements of samples obtained in the breathing zone of the workers during $8 \mathrm{~h}$ of work. The mean exposure of eight workers with the same type of work was calculated. Air was collected with a personal filter sampler (cassette holder for a 37-mm filter, Scantec Laboratory Equipment, Partille, Sweden) attached to the worker's collar and was sucked through a $0.8-\mu \mathrm{m}$ filter (Millipore AB, Västra Frölunda, Sweden) 
at a rate of $1.85-1.95 \mathrm{l} / \mathrm{min}$. The filter sampler also contained a cellulose-acetate filter impregnated with sodium-formiate for the adsorption and determination of gaseous fluorides $(23,24)$. The capacity of the suction pump (Casella AFC 123, Nordiska Miljoinstrument, Stockholm, Sweden) was controlled with a calibrated rotameter before, during, and after the sampling periods. The concentration of total airborne dust was determined by the weighing of the filter.

The exposure of inhaled dust and fluorides was estimated for each worker according to the type of work performed and the time of exposure. The workers were divided into low, medium, and high exposure groups according to the magnitude of the exposure. This estimation of extrapolated exposure was made with regard to total (lifetime) exposure and exposure during the year preceding the study, ie, during 1987. The magnitude of exposure was also estimated and categorized into the categories low and high when respirators had been in use.

During certain work tasks the exposure can be much higher than the measured background levels. Under such circumstances, measurements were taken during 15 min of work ("worst case estimate").

\section{Statistical methods}

The results have been presented as the mean values and the standard error of the mean (SEM). A P-value of $<0.05$ was considered significant. For the statistical analyses, the analysis of variance (ANOVA) and twotailed Student's t-test for independent observations were used. The statistical analyses of the lung function data were performed with the use of the percentages of the predicted values. The statistical evaluation of bronchial reactivity was performed by means of the Mann-Whitney U-test.

\section{Results}

One subject in each group had mild asthma and pollen rhinitis. However, all of the other participants were free from present and former allergic symptoms of the skin and airways. None of the participating subjects had considerable symptoms from the airways, such as coughing, phlegm, or dyspnea (ie, none had symptoms of chronic bronchitis)

\section{Lung function}

The lung function of the referents was normal in comparison with the predicted normal values of all the parameters measured except $\mathrm{TL}_{\mathrm{COSB}}$, which was reduced $(\mathrm{P}=0.022)$ (table 1$)$.

In the potroom workers, significant decreases in $\mathrm{FEV}_{1.0}(\mathrm{P}=0.004), \mathrm{MEF}_{50}(\mathrm{P}=0.006)$, and $\mathrm{TL}_{\mathrm{COSB}}$ $(P=0.044)$ and a significant increase in residual volume $(P=0.049)$ were observed when these subjects were compared with the referents (table 1). With regard to all the other lung function values, there were no significant differences between the two groups even if a tendency towards increases in CC/TLC \% $(\mathrm{P}=$ $0.059)$ and mean transit time $(\mathrm{P}=0.094)$ were observed in the exposed group.

There was no significant difference (ANOVA) in the lung function of the workers with high and those with low exposure (figure 1). This finding was valid for both total dust and fluorides, total life exposure, and the exposure during the preceding year (ie, 1987). In addition, when the use of respirators was taken into consideration, the lung function did not differ between the high and low exposure groups.

\section{Bronchial reactivity}

The $\mathrm{PC}_{20} \mathrm{PEF}$ could be determined for only one of the referents and three of the exposed workers. All of

Table 1. Lung function of 38 aluminum potroom workers (exposed subjects) and 20 healthy referents. The means, as the percentage of the predicted values, and the $95 \%$ confidence intervals $(95 \% \mathrm{Cl})$ for the means are given. If the $95 \% \mathrm{CI}$ does not include $100 \%$, the difference between the respective mean value and the predicted normal value is statistically significant. $\left(\right.$ FEV $_{1.0}=$ forced expiratory volume in $1 \mathrm{~s}, \mathrm{MEF}_{50}=$ maximal expiratory flow at $50 \%$ of the expired forced vital capacity, $T L_{\operatorname{CosB}}=$ single breath pulmonary diffusion capacity for carbon monoxide, NS = not significant)

\begin{tabular}{|c|c|c|c|c|c|}
\hline \multirow{2}{*}{ Lung function variable } & \multicolumn{2}{|c|}{ Exposed subjects } & \multicolumn{2}{|c|}{ Referents } & \multirow{2}{*}{ P-values ${ }^{a}$} \\
\hline & Mean & $95 \% \mathrm{Cl}$ & Mean & $95 \% \mathrm{Cl}$ & \\
\hline Total lung capacity & 97 & $94-101$ & 99 & $93-103$ & NS \\
\hline Vital capacity & 93 & $90-95$ & 97 & $92-101$ & NS \\
\hline Residual volume & 117 & $109-126$ & 104 & $93-113$ & 0.049 \\
\hline CCITLC $\%{ }^{\circ}$ & 107 & $103-112$ & 100 & $95-106$ & NS \\
\hline $\mathrm{FEV}_{1.0}$ & 93 & $90-96$ & 101 & $96-106$ & 0.004 \\
\hline $\mathrm{FEV} \% \mathrm{c}$ & 101 & $99-103$ & 104 & $101-107$ & NS \\
\hline Mean transit time & 101 & $95-106$ & 93 & $85-101$ & NS \\
\hline $\mathrm{MEF}_{50}$ & 81 & $75-86$ & 95 & $86-104$ & 0.006 \\
\hline $\begin{array}{l}\text { Change in the nitrogen concentration } \\
\text { per liter of expired air }\end{array}$ & 105 & $93-117$ & 110 & $82-137$ & NS \\
\hline$T L_{C O S B}$ & 88 & $85-92$ & 94 & $89-99$ & 0.044 \\
\hline
\end{tabular}

a The P-values indicate the differences between the two groups (two tailed Student's t-test for independent observations).

b $\mathrm{CC} / \mathrm{TLC} \%=(100 \times$ closing capacity $) /$ total lung capacity.

c $\mathrm{FEV} \%=(100 \times$ forced expiratory volume in $1 \mathrm{~s}) / \mathrm{slow}$ vital capacity. 
the other subjects tolerated the highest methacholine concentration $(32 \mathrm{mg} / \mathrm{ml}$ ) without a decrease in peak expiratory flow of $\geq 20 \%$. The $\mathrm{PC}_{10} \mathrm{PEF}$ could be determined for eight of the referents and 13 of the exposed subjects. The mean was $10.0($ SEM 2.7$) \mathrm{mg} / \mathrm{ml}$ for the exposed group and 15.6 (SEM 3.4) $\mathrm{mg} / \mathrm{ml}$ for the reference group. There was no significant difference between the two groups $(P=0.45)$.

\section{Exposure to inhaled alumina and fluorides}

The exposure data have been summarized in table 2 . The mean exposure values were 1.77 (range $0.49-4.5$ ) $\mathrm{mg} / \mathrm{m}^{3}$ for total dust and 0.31 (range $0.1-0.5$ ) $\mathrm{mg} / \mathrm{m}^{3}$ for total (gaseous and particulate) fluorides.

The "worst case estimates" showed mean values for gaseous fluorides of up to $3.13 \mathrm{mg} / \mathrm{m}^{3}$ during work with gas scirt exchanges.

\section{Discussion}

In Sweden there is only one aluminum plant (GA Metall) located in Sundsvall in the middle of the country. Most of the plant workers use respirators to protect themselves against airborne contaminants. The concentration of airborne alumina and fluorides in the factory was only $15-20 \%$ of the respective Swedish exposure limit, which is $10 \mathrm{mg} / \mathrm{m}^{3}$ for alumina and 2 $\mathrm{mg} / \mathrm{mm}^{3}$ for fluorides. The exposure measurements were performed during $8 \mathrm{~h}$ of ordinary work in the plant. During certain work tasks, such as gas scirt exchanging, however, the exposure can be higher, and this "worst case estimate," measured during $15 \mathrm{~min}$, can exceed the Swedish exposure limits for gaseous fluorides (highest level was $3.13 \mathrm{mg} / \mathrm{m}^{3}$ ) for short periods of time.

The objective of the present study was to investigate all of the nonsmoking potroom workers in the GA Metall aluminum plant and to recruit the referents from the unexposed employees in the same factory. The number of nonsmoking employees not working in the potrooms was limited, and therefore it was not possible to match the groups with regard to age (mean age being nine years higher for the reference group). Thus the lung functions of the groups were compared from calculations of all the lung function variables as the percentage of predicted values, the confounding effect of age thereby being eliminated.

There was a highly significant decrease in the $\mathrm{FEV}_{1.0}$ of the exposed group when these workers were compared with the referents, and obstructive lung function impairment was therefore indicated for the aluminum potroom workers. The group mean value of the $\mathrm{FEV}_{1.0}$ was however modestly decreased $(93 \%$ of the predicted value), and this finding congrued with the fact that all of the subjects in the exposed group were free from airway symptoms. The lack of correlation between lung function and the magnitude of exposure indicates that there is no dose-response rela- tionship at this low range of exposure. Another possible explanation is that our methods of measuring exposure did not adequately discriminate between different doses of inhaled contaminants in this low range of exposure. The modest reduction in the $\mathrm{FEV}_{1.0}$ was accompanied by an increase in residual volume, and these results suggest that the obstruction was mainly peripheral. This hypothesis is also supported by the
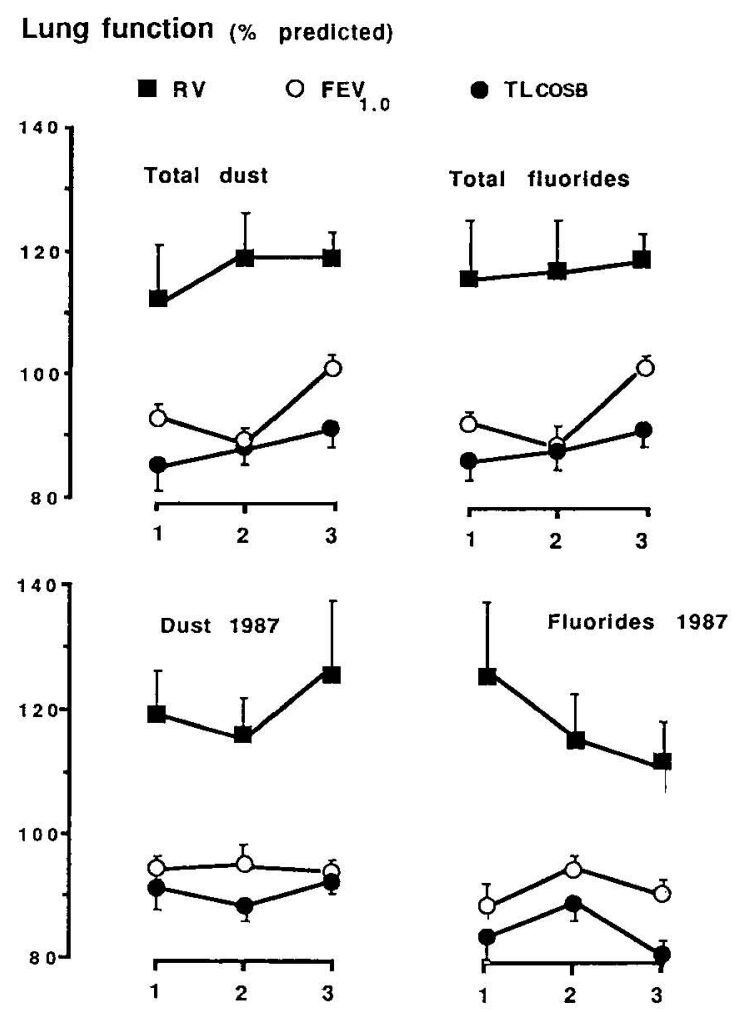

Figure 1. Relationships between the exposure to alumina and fluorides (total, ie, lifetime, exposure and exposure during the year preceding the study, ie, 1987) and the lung function of 38 aluminum potroom workers. The means and standard errors of the means are presented. $(1=$ low, $2=$ medium, and $3=$ high exposure; $R V=$ residual volume, $F E V_{1.0}=$ forced expiratory volume in $1 \mathrm{~s} ; \mathrm{TL}_{\mathrm{cos}}=$ single breath pulmonary diffusion capacity for carbon monoxide)

Table 2. Classification of the aluminum potroom workers $(\mathrm{N}=38$ ) according to the magnitude of their exposure throughout their lifetime and during the preceding year (ie, 1987).

\begin{tabular}{lccc}
\hline & \multicolumn{3}{c}{ Exposure group } \\
\cline { 2 - 4 } Exposure & Low & Medium & High \\
& $(\mathrm{N})$ & $(\mathrm{N})$ & $(\mathrm{N})$ \\
\hline Lifetime & & & \\
$\quad$ Total dust & 10 & 18 & 10 \\
$\quad$ Total fluorides & 12 & 16 & 10 \\
Preceding year & & & 8 \\
$\quad$ Total dust & 13 & 17 & 17 \\
$\quad$ Total fluorides & 8 & 13 & \\
\hline
\end{tabular}


finding of an impaired $\mathrm{TL}_{\mathrm{COSB}}$ and the tendency towards an increase in CC/TLC \% in the exposed group. These small changes in lung function were not associated with symptoms of asthma in the present study.

The findings of obstructive lung function impairment without asthmatic symptoms in the aluminum potroom workers is in agreement with the results of some earlier studies (2). However, other investigations have found an increased prevalence of bronchial asth$\mathrm{ma}$ in aluminum potroom workers $(5,6)$. We found no alteration in the slope of the alveolar nitrogen plateau, which is the best discriminant for the early detection of the type of peripheral airway obstruction observed in tobacco smokers (25). The pathophysiological mechanism behind this change in the nitrogen concentration per liter of expired air is not clear, but a development of centrilobular emphysema might be of importance. Hence the minor airway obstruction found in the aluminum potroom workers of the present study does not seem to reflect the early changes of emphyse$\mathrm{ma}$, but rather seems to resemble the changes observed in chronic obstructive pulmonary disease without emphysema. The finding of asthma in aluminum workers in other studies supports this hypothesis.

In the present study we found no difference in bronchial reactivity between the exposed workers and the referents. Thus the bronchial obstruction was neither accompanied by asthmatic symptoms nor by bronchial hyperreactivity. This finding is not in accordance with earlier findings of bronchial hyperreactivity against histamine (1) and methacholine (3) among aluminum potroom workers. This difference may, at least partly, be explained by the decision to select only nonatopic subjects for work at the aluminum plant in the present study. In the investigation by de Vries et al (1), the concentration of airborne fluorides was however approximately 13 times higher than the concentration in the present study. This difference in exposure seems to be the most probable explanation for the discrepancy between the occurrence of bronchial hyperreactivity in the aluminum potroom workers of the present study and the findings of de Vries et al (1).

\section{Acknowledgments}

The authors thank Mr U Bohlin, Director, GA Metall, for providing the facilities with which to complete this study and the employees of GA Metall for participating. The expert technical assistance of Ms G Johansson, Ms B Holm, Ms C Åkesson, Ms B-M Sundblad, Mr B Fernstrom, Ms A Gustavsson, and the staff of the Department of Clinical Physiology at the Sundsvall Hospital is gratefully acknowledged.

This study was supported by grants from the Work Environment Fund (AMF 87-0921), the Swedish HeartLung Foundation, and the Swedish Medical Research Council (16X-405).

\section{References}

1. de Vries K, Löwenberg A, Coster van Voorhout HEV, Ebels JH. Langzeitbeobachtungen bei Fluorwasserstoffexposition. Pneumologie 1974;150:149-54.

2. Chan-Yeung M, Wong R, MacLean L, et al. Epidemiologic health study of workers in an aluminium smelter in British Columbia. Am Rev Respir Dis 1983;127: 465-9.

3. Simonsson BG, Sjöberg A, Rolf C, Haeger-Aronsen B. Acute and long-term airway hyperreactivity in aluminium-salt exposed workers with nocturnal asthma. Eur J Respir Dis 1985;66:105-18.

4. Saric M, Zuskin E, Gomzi M. Bronchoconstriction in potroom workers. Br J Ind Med 1979;36:211-5.

5. Bruusgaard A. Astmalignende sykdom blant norske aluminiumarbeidere [Asthma-like disease in Norwegian aluminum plant workers]. Tidsskr Nor Laegeforen 1960;17:796-7.

6. Saric M, Jasminka G-C, Gomzi M, Stilinovic L. The role of atopy in potroom workers asthma. Am J Ind Med 1986;9:239-42.

7. Maestrelli P, Marcer G, Clenfero E. Occupational asthma in the aluminium industry. Eur J Respir Dis 1981; 62(suppl 113):92-3.

8. Kaltreider NL, Elder MJ, Cralley LV, Colwell MO. Health survey of aluminium workers with special reference to fluoride exposure. J Occup Med 1972;14: $531-41$.

9. Discher DP, Breitenstein BD. Prevalence of chronic pulmonary disease in aluminium potroom workers. $J$ Occup Med 1976;18:379-86.

10. Mitchell J, Manning GB, Molyneux M, Lane RE. Pulmonary fibrosis in workers exposed to finely powdered aluminium. $\mathrm{Br} \mathrm{J}$ Ind Med $1961 ; 18: 10-20$.

11. McLaughlin AIG, Kazantzis G, King E, Teare D, Porter RJ, Owen R. Pulmonary fibrosis and encephalopathy associated with the inhalation of aluminium dust. Br J Ind Med 1962;19:253-63.

12. Swensson $\AA$, Nordenfelt O, Forssman S, Lundgren $\mathrm{K}$ D, Öhman H. Aluminium dust pneumoconiosis: a clinical study. Arch Gewerbepath Gewerbehyg 1962;19: $131-48$.

13. Musk AW, Greville HW, Tribe AE. Pulmonary disease from occupational exposure to an artificial aluminium silicate used for cat litter. $\mathrm{Br} \mathrm{J}$ Ind Med 1980;37: $367-72$.

14. DuBois AB, Bothelo SY, Bedell GN, Marshall R, Comroe JH. A rapid plethysmographic method for measuring thoracic gas volume; a comparison with nitrogen washout method for measuring functional residual capacity. J Clin Invest 1956;35:322-6.

15. Grimby G, Söderholm B. Spirometric studies in normal subjects: III. static lung volumes and maximum voluntary ventilation in adults with a note on physical fitness. Acta Med Scand 1963;173:199-206.

16. Berglund E, Birath G, Bjure J, et al. Spirometric studies in normal subjects: $I$. forced expirograms in subjects between 7 and 70 years of age. Acta Med Scand 1963; 173:185-92.

17. Hedenstierna G, Jorfelt L, Bygdeman S. Flow-volume curves in healthy non-smokers and in smokers. Clin Physiol 1981;1:339-48.

18. Macfie AE, Harris EA, Whitlock RML. Transit-time analysis of the forced spirogram in healthy children and adults. J Appl Physiol 1979;46:263-7.

19. Morris FJ, Temple WP, Koski A. Normal values for the ratio of one-second forced expiratory volume to forced vital capacity. Am Rev Respir Dis 1973;108:1000-3.

20. Hedenström H, Malmberg P, Fridriksson HV. Reference values for lung function tests in men: regression equations with smoking variables. Ups J Med Sci 1986;91:299-310.

21. Quanjer $\mathbf{P H}$, ed. Standardized lung function testing. Clin 
Resp Physiol (Bull Eur Physiopathol Respir) 1983; 19(suppl 5).

22. Salorinne $Y$. Single-breath pulmonary diffusing capacity: reference values and application in connective tissue diseases and in various lung diseases. Scand $\mathbf{J}$ Respir Dis 1976;suppl 96: $84 \mathrm{p}$.

23. Jahr I, Guthe T. The health of aluminium smelters operators, surveillance of fluorides. Düsseldorf: European Primary Aluminium Association, 1979.

24. Guthe T, Nordheim E. Håndbok för helsevern og ar- beidsmiljöovervåkning i primär aluminiumindustri [Health service in aluminum plants]. Oslo: Aluminiumindustrins Miljösekretariat, 1984.

25. Hedenström H, Malmberg P. Optimal combinations of lung function tests in the detection of various types of early lung disease. Eur J Respir Dis 1987;71:273-85.

Received for publication: 10 March 1989 